\title{
Affective development in university education
}

\author{
PETER GROOTENBOER \\ Griffith Institute of Educational Research \\ Griffith University \\ Gold Coast, Queensland
}

\begin{abstract}
There seems to be an increasing requirement for university courses and programs to develop students' affective qualities (beliefs, values, dispositions and attitudes). This study explored the ways academics determined what the desirable qualities were for their particular disciplines and the pedagogical strategies and approaches they used to develop them. The participants were able to articulate certain beliefs, values and attitudes that were central to their discipline, although they appeared to be assumed and somewhat tacit in nature. The teaching and assessing of affective qualities was seen as problematic by the participants in the study, owing to inadequate policy structures of the University, but the data revealed some practical teaching approaches. It was clear from this initial study that there is still a great deal of research and scholarship required in this area.
\end{abstract}

Keywords: affective development, university teaching, beliefs, values, attitudes

\section{Introduction}

When students are undertaking tertiary study they develop knowledge, skills and affective qualities (i.e., values, beliefs, dispositions and attitudes). While the knowledge and skills students are required to learn in various programs appears to be relatively clear, there is less clarity about what affective qualities students should develop, and even less understanding about how they might be developed (Harrison, 2008).

Interest in affective development in the tertiary sector is not new. Indeed, the seminal work of Krathwohl, Bloom, and Masia (1964) was undertaken to establish a taxonomy of educational objectives for the affective domain in the university sector. A number of studies have explored the general affective development of students through their tertiary education (e.g., Feldman \& Newcomb, 1969; Pascarella \& Terenzini, 1991), and they have noted that graduates develop greater awareness of their interdependence and more liberal attitudes (Boylan, 2002). In recent years, many universities have acknowledged and articulated affective factors in their statements of graduate attributes. While these graduate attributes are not only affective in nature, they do have a significant affective quality. Therefore, while this study did not particularly focus on graduate attributes, they do form a significant feature of the current tertiary educational context (see Barrie (2004) for a detailed discussion of graduate attributes). Furthermore, values and ethics often underpin professional practice in the employment fields targeted by tertiary courses. Accordingly, it is recognised, in many tertiary professional degree programs, that these affective qualities are needed in those programs. Moreover, regardless of the field of study, tertiary education providers invariably place some emphasis (sometimes implicit rather than explicitly stated) on values and aspects of emotion. This is to varying degrees, depending on the discipline and the circumstances. Still further, while students are developing their knowledge and skills in their particular fields, they are also developing beliefs about their discipline, the 
values intrinsic to those fields, and their own values as operators in that field (Hargreaves 1998).

Indeed, it is widely recognised that a good education, at any level, focuses on the development of 'the whole person', and therefore, good learning in the university context should be concerned with affective qualities. With this in mind, the current project focussed on the deliberate and intentional development of affective qualities in programs in one Australian university.

\section{The Affective Domain}

The affective domain has been variously defined in the literature, but generally it includes aspects such as beliefs, values, attitudes and emotions (Grootenboer, 2003). Although not universally accepted, the components of the affective domain are often defined as those beyond the domain of cognition. McLeod (1992) suggested that the affective domain could be conceptualised as a sort of continuum:

... we can think of beliefs, attitudes and emotions as representing increased levels of affective involvement, decreased levels of cognitive involvement, increasing levels of intensity of response, and decreasing levels of response stability. (p. 579)

Based on this understanding, there seems to be a direct connection between some aspects of the affective domain (e.g., between beliefs and values) but not others (e.g., between values and emotions). While these conceptions of the affective domain are helpful, it is difficult to clearly define this complex and intricate phenomenon. However, the difficulty in precisely defining the affective domain should not diminish its relevance in tertiary education, particularly given its ubiquitous nature.

\section{The Development of Affective Views}

Affective views and responses are seen to develop through experience, rather than being carefully thought-through or logically considered (Rokeach 1968). In this sense, beliefs and attitudes are regarded as growing in a more organic fashion, or as 'just happening'. Furthermore, affective views are thought to be stored in episodic memory, couched in significant events in individuals' personal experiences, meaning that they may not be accessible through cognitive strategies such as critical evaluation or logical review (Nespor 1987). Thus, the lack of deliberate attention to developing affective responses can mean that they are often tacit, and yet they can powerfully influence decision-making and behaviour (Pajares 1992).

However, the explicit nature of affective outcome goals for university graduates (as outlined in policy documents such as those listing 'graduate attributes') implies the need for a more intentional approach to affective development. That is, while the development of values, beliefs and attitudes has always been inherent in university programs, there now seems to be a growing emphasis on making these more particular and explicit, as is revealed by university documents such as those listing 'graduate attributes' (Hoban et al. 2004). Hence, there is an imperative to consider how these affective qualities and views can be 'taught' (Nillsen 2004). However, this appears to be an under-researched and undertheorised question in university education (Harrison, 2008). Indeed, Kezar (2005) suggests that there is a real problem with most scholarship on tertiary and organisational learning, 
because learning is too narrowly defined in terms of knowledge or intelligence development, and it thereby ignores the affective dimension.

\section{The study}

The aim of the study is to explore the ways in which academics in one university determined the beliefs, values and attitudes that they considered important to be taught in their programs of study, how they went about the teaching of these affective attributes and the problems that they faced. In the following sections, the context and methods of the study are outlined. This is followed by a presentation and discussion of the findings.

\section{Context}

The project was a case study of one multi-campus university in Australia. The university offers a range of under-graduate and post-graduate programs, and it has a particular focus on providing tertiary education for the professions. A significant proportion of the university's students study through 'distance education' programs.

The University has devoted significant energy to developing a set of "Graduate Attributes", and these are articulated in its Strategic Plan. These graduate attributes have aspects that relate to knowledge, skills and affective qualities. The examples cited below have a significant affective component;

[The University] Graduates will also demonstrate:

an understanding of, and commitment to, open inquiry, ethical practice, social justice, tolerance and cultural diversity

an appreciation of the need for a balance between economic sustainability and environmental sustainability.

Without questioning the university's capacity to make such a definitive claim, in order for a graduate to have these attributes (and others), they would need to hold environmental values, beliefs about social responsibility, and a positive attitude towards different cultural groups, just to name a few underlying affective characteristics. Also, because "education for the professions" is a key platform of the University, it is expected that many of its programs would have a significant affective component. For example: a teacher graduate would need to value learning and have a positive emotional response to children; a mathematics graduate would need to have a fascination for mathematics and a joy for solving mathematical problems; and a police graduate would need to value the law and have a positive attitude towards all sectors of the community. While this affective dimension of students' learning may not be overtly considered or addressed in the preparation, delivery and assessment of learning experiences, nevertheless, the Graduate Attributes and professional programs clearly contain qualities that are affective in nature. This implies that there is a clear agenda that these affective attributes will be 'taught' and 'assessed' (Carroll 2004).

\section{Research Questions}

This project explored the affective dimension of university education, and the study specifically centred on the deliberate and intentional growth of beliefs, values and attitudes 
from the institution's perspective (i.e., the affective views the university promotes at the institutional, faculty, school and subject levels). The following research questions guided the project:

1. How do staff, schools and faculties decide which affective qualities are important for their graduates?

2. How do staff, schools and faculties develop affective qualities in their students through their teaching?

3. How do staff, schools and faculties assess affective development?

4. What ethical issues are involved with promoting particular affective views?

\section{Method}

The study was qualitative in nature and employed an interpretative framework. Data were collected in two phases as outlined below. Interviews were conducted with participants from across the university campuses and a range of discipline areas, including Education, Science, Nursing, Midwifery, Policing and Business. Although the aim was not to develop a 'theory', the data were analysed using grounded theory techniques. Coding themes were determined from the literature and the research questions, and other themes emerged as the data analysis progressed.

\section{Phase 1: Document analysis}

A selection of documents was identified, collected and analysed in order to identify where and how affective factors were recognised in the University, and the nature of the affective qualities that were deemed significant. In all, 24 documents were analysed, including the University Handbook, seventeen subject outlines and statements, the University graduate profile, and five discussion papers where affective aspects of the graduate profile were considered. The identification, collection and analysis of these documents was the first task undertaken in the project.

\section{Phase 2: Course coordinators and teaching academics: semi-structured in-depth interviews}

One course coordinator and one teaching academic from each Faculty (selected in consultation with the Deans and/or Heads of Schools) were interviewed. Interviewing participants from across the Faculties ensured a breadth and variety of perspectives of the topic. The ten interviews focussed on affective development within particular disciplines and were structured around the following broad themes:

- Desirable affective qualities for the graduates within their discipline (e.g., what values would you like your graduates to hold?);

- Processes for deciding upon these affective qualities (e.g., do you have discussions about beliefs that imbue your discipline?);

- Approaches for developing these affective qualities (e.g., how do you overtly promote certain attitudes in your classes?);

- Approaches for assessing these qualities (e.g., how do you know if students have developed the desired values?); and

- Ethical issues about affective change (e.g., do you see any ethical issues in promoting certain beliefs or attitudes?).

The interviews provided rich data about how each teaching academic viewed affective 
development in their subjects, some of the methods and teaching approaches they used to develop affective qualities, and issues and concerns that were seen to hinder desirable affective development of students. These interviews were audio-taped and transcribed. The transcripts were then returned to the participant concerned for editing, comment and verification.

\section{Findings and discussion}

Throughout the study it was clear that issues surrounding affective development were significant at the University, but the complexity and difficulty in trying to promote and achieve affective development in a university context were also apparent. Before presenting the views of the academic staff obtained through the interviews, a brief synopsis of the particular University context is outlined, below, by summarising some of the documentary references to affective dimensions. This is followed by findings on academics' perceptions of important affective elements in their courses, the sources for these perceptions, the factors involved in changing students' affective qualities and views, and the teaching approaches that have been adopted for affective development. (Note that pseudonyms are used throughout this article).

\section{Affective factors in the University's documents}

A broad review of the range of documents, outlined earlier, revealed a commitment to affective development as an integral part of all of the University's programs. Indeed, the university itself has a Statement of Values that is published in the annual Handbook. Furthermore, the Student Charter (also printed in the Handbook) outlines a number of expectations that students can have of the university (and vice-versa), including affective aspects such as: "a supportive, harmonious and positive learning community of which you are a valued member ...".

A fundamental avenue for the articulation and promotion of desirable affective qualities has been through the University statement of Graduate Attributes. This list of graduate attributes has been approved by the University Council (Minutes of meeting number 36) and the University Senate (Senate minutes issued February 2006). The requirement is that all Bachelor degree courses and sub-degree awards "will foster in their graduates the attributes ..." (emphasis added). As outlined in a previous section, these attributes have a significant affective flavour and dimension. One example of these attributes is:

By the conclusion of their studies, students are able to ... demonstrate an understanding of, and commitment to, values-driven practice in their field of study that takes account of open enquiry, ethical practice, social justice, cultural diversity, reconciliation and environmental sustainability.

It is clear from this statement that the university has an expectation that students will not only have a cognitive knowledge of certain values and beliefs, but personal commitment to those views and positions. However, it is not clear what commitment the University has to achieving these ideals beyond these statements. Nor is it clear whether the ethical issues associated with these definitive goals been considered.

There has been some attempt to encourage these overall attributes at the faculty and school level, where a number of discussion papers and documents have been prepared that address the Graduate Attributes in their particular context. For example, the School of Education 
prepared a statement of Aspirations for their students and graduates. The aspirations included (emphasis added):

- ... graduates to be educators with a passion for their subject/discipline, pedagogy and their students' learning; and people with a passion and commitment to the knowledge and technical skills of their discipline(s) and to their ongoing learning

- ... graduates to be sensitive to the rights and needs ...

- ... graduates to be collectively engaged and have positive relationships ...

- ... graduates to be committed to education as a process of critical transformation ...

- ... graduates should have a social conscience and commitment to improving their community.

Here again, it is clear that a thorough technical knowledge is not sufficient. Rather, graduates are expected to have particular values, beliefs and personal qualities, and it is expected that these be developed through the school's programs, courses and subjects.

The mandate to develop affective views and qualities at the University is clear. Again, the statements are not implemented at a teaching, learning and assessment level. However, the factors involved and the ideas, views and strategies of a number of course coordinators and teachers, about how this might be done, are presented in the sections that follow.

\section{Desirable affective qualities}

As noted above, interviews were conducted with participants from a range of discipline areas across the university. In each case, the participants discussed the desirable affective qualities that they sought to develop through their programs, courses and subjects. All of the participants were able to list some beliefs, values and attitudes that they saw as important, some of which were quite generic, while others were more discipline-specific.

The more universal qualities included values and attitudes about ethics, a sense of empathy and care, and a disposition for life-long learning. The focus on ethics is not surprising considering the professional nature of many of the University's courses and the centrality of ethical conduct in professional practice. For many of the participants, it seemed that ethical values were a given, and, as such, they were unquestionably accepted. Such ethical values were expressed in various ways, for example:

We hope they [students] develop an ethical consciousness. (Alex, Science)

I'd like the students to be continually questioning the role of technology in learning and the ethical implications. (Mary, Education)

... you need to have a sense of ethics and justice and a whole range of values ... (Alice, Nursing)

Indeed, a number of courses at the University have whole subjects devoted to ethics within their field (e.g., in the School of Business: Security, Privacy and Ethics), highlighting the importance of this affective quality for University graduates as they embark on their professional careers.

The more disaggregated needs for empathy, thoughtfulness and care were also widely noted by the participants, including those from outside the so-called caring professions of 
teaching, nursing and midwifery. These included the need to develop a caring attitude to the environment, thoughtfulness in working in teams, and "empathy, appreciation and understanding of difference" (Emma, Policing). Finally, the desire to see graduates have a disposition to life-long learning was noted by participants across a range of disciplines and was expressed as developing an "interest in learning for its own sake" (Emma, Policing), and being "enthusiastic and excited about learning" (Mary, Education).

\section{Determining desirable affective qualities}

Thus, throughout the study, it was clear that the participants were aware of certain affective qualities that they felt were important for their graduates to possess and display. In response to this finding, the participants were asked how the appropriate, desirable and necessary graduate beliefs, values, attitudes and dispositions were determined. One clear way that these affective qualities were determined was through professional standards or other external criteria that were in some way prescribed by an external professional body. In this sense, there was no negotiation; nor was any need for debate perceived, as the affective qualities being prescribed were seen as essential and central to the professional practice in that field. Therefore, it was deemed important that students develop these views and virtues through their programs. For example, the competency standards published by the Midwifery Council clearly promote a woman-centred philosophy of midwifery, and the academics who work on the midwifery program explicitly build their program on that same central value.

Not all the discipline areas or fields of practice had a list of externally mandated criteria but, even in those that did, there were other unarticulated affective qualities that were seen as important and desirable for graduates. Again, it often seemed that these were fairly uniformly accepted within the discipline and somewhat tacitly known. That said, there were also other beliefs and views that were noted as contestable even amongst university colleagues. Hence, participants were asked about how they decided what the appropriate affective qualities (not including the externally mandated ones discussed above) should be to underpin their subjects and courses. Almost without exception, the participants said that there was no deliberate process for discussing, evaluating and determining the desirable affective qualities for their graduates. In some cases, particularly where there was a small teaching team, such processes were seen as unnecessary because these things were just known and assumed to be shared. Others suggested that determinations might be made through informal conversations or as a side-issue to another topic of discussion. Furthermore, course coordinators were quite clear that they did not want to be prescribing values, positions or beliefs that their colleagues had to teach or promote.

\section{The marginalisation of affective development and university policy}

It was evident, throughout the study, that, in general, it was quite difficult to actually promote affective development within the structures and policies of a university (Grootenboer, 2003), let alone require specific values, attitudes and dispositions within particular programs (Kempner \& Taylor 1998). This appeared to be because of the range of ethical and moral dilemmas inherent in demanding certain values and beliefs of students, which requires a great deal of thoughtful consideration. Certainly, the participants in the study were concerned that graduates from their programs could graduate without any commitment to the values, ethics and beliefs that were seen as crucial to practice in their 
field.

We can guarantee that they learn them [appropriate beliefs and values] but we can't guarantee that

they believe in them and what they will do in the real world when they graduate. The only thing we

can do is give them the opportunity to acquire those that we think are appropriate attributes and

hope that they will act on them. (Alice, Nursing)

However, it should be noted that many of the participants were confident that most of their graduates held beliefs and values that were largely consistent with those of their field. In many cases, it was felt that, because students enrolled in programs that had already captured their interest, including the affective qualities associated with the discipline, they were also somewhat sympathetic to the values and attitudes that imbued their university program.

What was clear throughout the data was the difficulty in formally assessing affective attributes using the tools and methods that were currently used to assess other dimensions such as knowledge and skills. The assessment of affective qualities was seen as particularly problematic for a number of the participants. While many were able to evaluate students' affective qualities in informal ways, there was less confidence about marking and formal assessments (e.g., through assignments or tasks that were used to determine student grades). This point is well illustrated in the following quotation from one of the participants:

\begin{abstract}
Apart from assessing their knowledge of ethics and morals in examples, we don't assess whether they actually have the qualities themselves. We might assess their knowledge of ethics and morals, but of course that is not assessing their ethics and morals, it just assesses their understanding of what an ethical approach might be. Whether they apply that approach we can't assess. I'd be surprised if anybody truthfully said that they assess qualities like this and based on that assessment, were confident enough to say that the student had those qualities, because students will answer questions in order to pass whatever it is you are assessing. (Alex, Science)
\end{abstract}

Universities are award granting institutions, and as such they are required to measure and assess whether an individual has met the requirements for a particular qualification. These processes are couched in the history and tradition of tertiary education. But, in more recent times, there has also been a range of political, legal and financial pressures affecting these processes. Within this context, assessment in the university is supposed to be rigorous and objective, and this has led to evaluation procedures that are largely based on measurement (Kempner \& Taylor 1998). In general, as outlined above, it was found that this works well for assessing candidates' knowledge and skills, but is not appropriate in many ways for promoting affective development. In short, despite the formal statements about affective development in university programs, it seemed that the teaching and learning environment of the university limited the requirement for students to have or develop certain beliefs, values, attitudes or dispositions. This raises some important questions about whether affective-type qualities can and should be formally assessed, and if so what technologies and approaches might be fruitful. 


\section{Developing and changing students' affective qualities and views}

In the previous section, it was argued that the beliefs, values and attitudes that students bring with them to their university program are influential in their graduating qualities. For example, one would hope that someone enrolling in an environmental science degree might have an interest in issues of conservation and sustainability. These affective qualities might be somewhat naïve, but nevertheless, sympathetic and amenable to the particular discipline that they have selected.

However, while this is no doubt the case in many respects, it is not always so simple. Participants reported that students can enter their programs with firmly held beliefs about professional practice in their field that can be tacit, tenacious and/or unavailable for reconsideration. For example, a preservice teacher may come from a very traditional educational background and they may begin their degree program with fixed formal beliefs about teaching and learning. These views and values may have been formed and reinforced over many years in the school system, and so their teacher education program may struggle to unsettle these prevailing views. Similarly, in the policing program, candidates may come from a police family, and they may have particular, and most likely, dearly held views about policing and the role of a police officer. Again, in this situation it may be very difficult to bring about any meaningful critical reflection on these affective views as the experiences of the university program would be minimal compared with the wealth of experience outside the tertiary program.

An allied concern also emerged in the data because of the professional nature of many of the University's programs and their practicum components. It was reported that these practical placements are very influential in moulding students' beliefs and attitudes because they have the significant legitimising effect of being "real experience" (as opposed to the university-based subjects). Indeed, this is the real world that the professional programs are preparing their students for, and so the affective attributes developed as part of their program should prepare the graduates for their practice. But it is also the case that professional graduates should be able to critically reflect upon and consider the prevailing beliefs, values and attitudes that are evident amongst the practising professionals in their field, and not necessarily accept them as fixed and always appropriate for changing times. For example, Celine (Education) commented about this dilemma in preparing primary school teachers:

Lots of students come to us believing that maths is taught formally through textbooks because that was what it was like for them. We try and show them another way ... but when they go on 'prac' they tend to see the old beliefs in action again, so ...!

She went on to discuss how the traditional beliefs and values about mathematics teaching and learning tend to be sustained because of the powerful wealth of experience the student teachers have had, and how the beliefs and values presented in their university subjects can be dismissed as not being "practical". The net result in these cases is that the underlying values, beliefs and dispositions towards this aspect of professional practice are not always as open to change as they should be.

Thus, because of the complexity of learning and affective development, it is unlikely that students' experiences prior to entry, or during the practical components of their program, will lead to affective attributes that are completely positive and enabling (or completely 
negative and disabling). Therefore, as has previously been argued, it is the responsibility of the university through its programs to help students develop the affective qualities and attributes that have been deemed as appropriate for their field or discipline.

\section{Teaching approaches that facilitate affective development}

One of the central aims of this study was to ascertain and understand some of the teaching approaches employed by academics to develop affective qualities with their students. Despite the limitations of the university system overall, as presented above, it was clear that the participants had thought through and developed some teaching approaches and strategies that were explicitly designed to promote reflective review of personal affective attributes and the prevailing values and attitudes of their discipline. As for the preceding discussion, these teaching strategies tended to be less formal and more interactive, although most of the participants also mentioned the use of lectures to address topics like ethics. The approaches outlined by the participants included:

- modelling,

- the "rub-off" effect,

- story telling,

- case studies,

- role playing, and

- first-person writing.

These are briefly discussed in turn below.

\section{Modelling}

A number of the participants reported that they needed to passionately hold and display the affective attributes that they desired for their students. The sense here was that, whatever they might say, the students would read them, and the modelled affective qualities would be the strongest form of communication about what is important. Of course, in the interviews it was clear that these academics were fervently passionate about their discipline, and many commented that it wasn't difficult for them to enact such values and beliefs because they were indeed committed to them. In this manner, they were in many respects just being themselves, and not 'putting on an act'.

One of the participants went on to suggest that "modelling is very powerful, and it is even more powerful when I debrief with the students about why certain things are modelled in a particular way - what values underpinned my actions" (Celine, Education). Through the interrogation of her professional practice with her students, this teaching academic not only displayed what certain appropriate affective traits look like in action, she also helped the students unearth the values, beliefs and attitudes that underpin it.

The teaching academic's sense of personal attachment and modelling of desirable affective attributes seemed to underpin, to a greater or lesser extent, many of the other strategies.

The "rub-off" effect

Another informal approach for facilitating affective development that is akin to the modelling strategy mentioned above was the so-called "rub-off" effect. This approach was largely unstructured, and relied again on academics having a personal and passionate 
commitment to the affective attributes they were promoting. In short, students acquired and appropriated the desirable dispositions, attitudes and values by spending time with the academics and developing a relationship with them. This relational approach was mentioned by a number of the participants, but they reported that it did require them to spend sufficient time with the students so that a relationship could develop. This, particularly in less formal teaching situations (e.g., workshops and tutorials) and in some other cases, involved time spent together outside of their programmed learning events. Quite a few of the participants also mentioned that finding the time and opportunities to be with their students in these ways was becoming increasingly difficult.

One of the participants discussed how a camp provided opportunities for students and academics to interact in a less formal setting.

I run field trips to a remote part of the country for students and there is plenty of opportunity to discuss things around the camp-fire, and during the course of the trips we can see attitudes changing. (Alex, Science)

Similarly, other participants talked about subjects that are structured differently from the standard semester of lectures, workshops and tutorials. In subjects where the students spent a considerable block of time together (like a block course or residential school), the participants reported that there was more opportunity to interact in a more intensive manner, and these times provided more opportunity for positive affective attributes to $r u b$ off.

\section{Story-telling}

Alongside the modelling of personally held values and attitudes, a number of the participants also used stories from their own professional experience to illustrate, exemplify and convey desirable affective qualities. These stories have the legitimacy of being from real experience, and as such they were often seen by the students as being plausible and important. Stories also enable the students to see and appreciate how particular values or ethics are enacted in practice, thus bridging the theoretical ideas of the formal teaching setting, and the pragmatic issues of practice. Of course, they also serve to strengthen the students' perceptions of the teaching academic's personal commitment to the particular professional affective attributes.

\section{Case studies}

Throughout the study, a number of the participants mentioned teaching and/or assessment activities that can broadly be called case studies. These took a range of forms, but, in general, they all allowed students to experience a particular event from a different perspective. The case studies provided opportunities to enter these experiences in more than just an academic manner, as the students had to engage with affective, conative, behavioural and cognitive concerns simultaneously. As such, the case studies provided learning situations that were more akin to the complexity of professional practice, including, to some extent, the emotional, ethical and values dimensions.

Emma (Policing) used a form of case study to allow students to empathise with the situations of others and to connect with the non-professional sides of their lives (e.g., as sons, daughters, parents, someone in need of assistance). In entering into and studying these cases, the students were able to appreciate and understand their professional role from "the other side", and be conscious of the affective attributes that they would want in a 
police officer. In other disciplines, cases from the professional field were used so students could grapple with the ethical issues involved, and learn to make moral judgements within the safe confines of a hypothetical or historical situation.

\section{Role playing}

Another popular way to allow students to enter into the experiences of others was through role playing. While some participants reported that some students were a little shy of acting with, and/or in front of their peers, role play was seen as a powerful tool for engaging students affectively in particular professional situations. In many ways, a role play is similar to a hypothetical case study, but the students have to respond physically and in the moment, meaning it can be more "real". However, it also has the potential to go beyond the confines of the particular subject of interest. One of the participants recounted how she used a role play so students had to engage with a situation where there were competing values, and they had to negotiate to come to a collective decision.

They get given the story of John and they are the multidisciplinary team. I put them in a circle and they have to be whoever they have been given and what they believe. Then they actually have to make a decision about John. (Alice, Nursing)

Through this role play activity, the students learn that it is just not as simple as acquiring the appropriate beliefs, values and attitudes for your field, but that in professional practice you also need to engage in negotiations and debates with others who may not share your views. These sorts of activities require students to move from just knowledge of ethics towards affective traits that enable them to make professional and ethically sound judgements, on which appropriate decisions can be made.

\section{First-person writing}

A final teaching approach that was mentioned by more than one participant was firstperson writing in assessable and non-assessable tasks. For a number of the participants, this sort of writing was done in some sort of journal. This teaching approach did not have the spontaneity or immediacy of the role play, but it did allow the students to engage in considering their values, beliefs and attitudes, and to express them in a personal manner. The power of this sort of writing is that it requires the student to write about themselves rather than "teachers" or "scientists" or "midwives" in general. The students need to express what they feel, value and think, rather than merely accede to some generic statements about professionals in their field. The consensus amongst those who employed this teaching strategy was that the students still needed to engage with the appropriate theory and literature, but they had to move beyond mere understanding and knowledge to personal commitment and proposed action. As such, the students' writing was usually value-laden, and affective to some degree, in nature.

\section{Concluding comments and recommendations}

While this study has been limited to just one university, it has been clear that the development of affective qualities has been accepted as an integral and important part of students' University education. However, it is equally clear that affective development is complex and difficult, particularly within the tertiary context. It is also clear that there is a difficult gap to be spanned between statements of affective graduate attributes and implementing teaching and learning strategies for their development; and that there are considerable barriers in university systems. 
Furthermore, it is debateable as to whether the university and academics can evaluate and comment upon graduates' affective attributes with any degree of certainty. That said, these findings don't diminish the need to promote the development of desirable affective qualities within the university's programs, particularly given the large number of programs that are professionally oriented. Moreover, students are always learning values, beliefs and attitudes through their tertiary education, and this present concern with affective development is really about being more overt and deliberate about those affective traits that are seen as desirable and even essential.

The academics interviewed for this study were able to articulate a range of teaching approaches that they employ to promote affective growth amongst their students. Furthermore, the participants were acutely aware of their own ethical responsibilities and concerns as they sought to engage students about values, beliefs, attitudes, morals and dispositions. As one participant stated; "I still need to allow people to make up their own minds. ... Forcing someone to believe in what you believe in is not ethical or moral." (Alex, Science). The participants were also clear about their limitations in trying to facilitate affective development, as indicated in this proverbial statement: "You can lead a horse to water, but you cannot make it drink".

In reviewing the findings of this study, there are implications for the development of tertiary teaching programs and research into learning in university contexts. I finish by briefly outlining four recommendations.

First, it is important that academics in particular discipline areas discuss and clarify the desirable affective attributes that underpin their field. In each discipline area there was, to a greater or lesser extent, some presumption of a shared understanding about what were considered desirable, or even essential, affective attributes. However, these values, beliefs, dispositions and attitudes did not appear to be discussed or explicitly evaluated, and so the acceptance of affective qualities was largely tacit. Given the importance of developing these desirable affective traits, it would seem important that academics discuss and evaluate their views so they may have some clarity about what attributes are indeed shared, and the affective qualities that they themselves still see as debateable.

Second, the practices and policies of universities need to be reviewed to see if more flexibility can be found to accommodate affective qualities. This is not a small or simple task given the range of traditions and influences that prescribe and constrain the teaching practices of universities. In this study it was clear that it is difficult to promote affective development within the current policies of the university that privilege the development of measurable attributes like skills and knowledge. In particular, it seems very hard to assess affective qualities in any formal way. Thus, affective development is often marginalised when considering what is actually seen as important.

Third, this study was limited to the perspective of one university through its documents and staff, and so the views of students, graduates and other stakeholders (e.g., employers) were not considered. These other perspectives (students, graduates and other stakeholders) need to be explored so there is a more comprehensive understanding of the issues of this study. 
Finally, there is a need for more research and development into teaching strategies and approaches that facilitate affective development. This study has begun to explore the teaching approaches employed by some academics to promote and facilitate the development of desirable affective attributes. It is clear that, in general, this is not that well understood, as is also evidenced by the limited literature available on the topic. Furthermore, there is a need for scholarship and research to develop theory that helps explain tertiary learning that incorporates an affective dimension.

\section{References}

Barrie, S. (2004). A research-based approach to generic graduate attributes policy. Higher Education Research and Development, 23(3), 261-275.

Boylan, H. (2002). Graduate attributes, why and how. Presented at the Building Learning Communities through Education: Lifelong Learning Conference, Yeppon, Queensland, Australia. $\quad$ Retreived November 9, 2009, from http://www.library.cqu.edu.au/conference/papers/Boylan.pdf

Carroll, M. (2004). Quality assuring the student experience: AUQA's findings. Presented at the Student Experience Conference, Charles Sturt University, Wagga Wagga, Australia.

Feldman, K.A., \& Newcomb, T.M. (1969). The impact of college on students. San Francisco, CA: Jossey Bass.

Grootenboer, P. (2003). Phenomenology: A window into the hearts of learners. Presented at the Contemporary Approaches to Research in Mathematics, Science, Health and Environmental Education Symposium, Deakin University, Melbourne.

Hargreaves, A. (1998). The emotional practice of teaching. Teaching and Teacher Education, 14(8), 835-854.

Harrison, N. (2008). Engaging identities in a regional university classroom. Higher Education, 56, 241-258.

Hoban, G., et al. (2004). A web environment linking university teaching strategies with graduate attributes. Journal of University Teaching and Learning Practice, 1(1), 10-19.

Kempner, K., \& Taylor, C. (1998). An alternative assessment to higher education outcomes. Higher Education, 36, 301-321.

Kezar, A. (2005). What do we mean by "learning" in the context of higher education. New Directions for Higher Education, 131, 49-59.

Krathwohl, D.R., Bloom, B.S., \& Masia, B.B. (1964). Taxonomy of educational objectives: The classification of educational goals. Handbook II: The affective domain. New York: David McKay.

McLeod, D.B. (1992). Research on affect in mathematics education: A reconceptualization. In D. Grouws (Ed.), Handbook of research on mathematics teaching and learning (pp. 575-596). New York: Macmillan.

Nespor, J. (1987). The role of beliefs in the practice of teaching. Journal of Curriculum Studies, 19(4), 317-328. 
Nillsen, R. (2004). Can the love of learning be taught? Journal of University Teaching and Learning Practice, 1(1), 13-24.

Pajares, M.F. (1992). Teachers' beliefs and educational research: Cleaning up a messy construct. Review of Educational Research, 62(3), 307-332.

Pascarella, E.T., \& Terenzini, P.T. (1991). How college affects students: Findings and insights from twenty years of research. San Francisco, CA: Jossey Bass.

Rokeach, M. (1968). Beliefs, attitudes and values: A theory of organizational change. San Francisco, CA: Jossey-Bass. 